\title{
Examining Primary School Students'perspectives on the Learning of English as a Foreign Language in Beninese Private Primary Schools
}

\author{
Jean-Marc Gnonlonfoun
}

Gri-digest/larpet/enset/unstim-a

\author{
DOI: $10.36348 /$ jaep.2020.v04i04.002 $\quad$ | Received: 27.03 .2020 | Accepted: 03.04.2020 | Published: 09.04 .2020 \\ *Corresponding author: Jean-Marc Gnonlonfoun
}

\section{Abstract}

This article aims to identify the beliefs about the teaching and learning of English as a foreign language of primary school students of a private school in the Littoral region in Benin Republic. Using the focus group technique, eighty-four students are interviewed following the Inventory of Beliefs on the English Language as the basis for the questions. The data from the four focus groups are interpreted with the semantic content analysis technique that allowed for the creation of categories of emerging themes related Englishing language learning, expectations and relevance of the language, and the motivation and anxiety it generates for the participants. The results show the different types of beliefs of the students, those that are closely related to the previous learning experiences that the participants have lived. CE1 and CE2 participants show a more positive vision of the role and usefulness of English in today's society, while CM1 and CM2 students are clearly more critical of the English classes they have had and their negative experiences in language learning.

Keywords: Beliefs, English teaching and learning, private primary school students, Benin context.

Copyright @ 2020: This is an open-access article distributed under the terms of the Creative Commons Attribution license which permits unrestricted use, distribution, and reproduction in any medium for non-commercial use (NonCommercial, or CC-BY-NC) provided the original author and sources are credited.

\section{INTRODUCTION}

The different aspects of the teaching and learning processes of modern foreign languages in Beninese primary schools still need to be studied in depth as well as in the implementation of government policies. Indeed, this research is interested in investigating the teaching and learning of English as a foreign language in primary schools in Benin, though it is neither widespread nor not yet truly compulsory to teach the subject. In addition, within the Beninese primary school curriculum, the time allocated for teaching the English language seems to be insufficient to effectively develop the four linguistic skills necessary for learning a foreign language (reading and listening comprehension, oral and written expression) [1].

\section{THEORETICAL FRAMEWORK}

The beliefs we have determine our way of acting and influence particular decision making. The sociocultural environment, motivation and context are some of the factors that participate in the type of beliefs that an individual may have about their own learning. Much research on the subject has shown that the beliefs of individuals affect their behavior in a decisive way [24]. Possessing a belief consists of acquiring a willingness of the subjects to act in a certain way and not in another, which is related to the fact that beliefs are the main guide of the actions of people. They are generalizations about cause and effect, and are influenced by internal representations of the world around us. They help us make sense of the world, and determine what we think and how we act. Therefore, the object of a belief circumscribes, delimits and determines in each particular circumstance the scope of possible responses. A belief is an attitude acquired by a person; it is determined by some situation learned at some points in their lives, which generates responses and behaviors regarding the particular issue.

Avella and Camargo [5] and Harmer [6], for their part, point out that for the effective learning of English, the intrinsic motivation of students towards the language and their own beliefs about it are fundamental, that is, they can determine the desire of the student for learning the language. These beliefs are due to the previous experiences that the students have had and that have marked and demotivated them to develop learning in the language. For this, the cognitive world of students must be understood: understanding what they believe, how they act and what factors negatively or positively influence the success of their language 
learning [7, 8]. This information about the cognitive world of the students is crucial to anticipate the difficulties or obstacles they may present when learning a language, since negative beliefs about a language and its learning can clearly constitute an important barrier to this learning taking place. It is very common to observe early that students of the school system self-determine that they will never learn a language other than their mother tongue, because they do not have the skills to do so. Unfortunately, this belief accompanies and negatively determines their learning.

Horwitz [9] is a pioneer in studies on the beliefs of learning a foreign language. He refers to them as complex constructs made up of previous learning experiences and cultural backgrounds that a person may possess. Beliefs are also fueled by processes of interaction with others and are highly context-sensitive, that is, subjects from similar contexts tend to develop similar beliefs. The study by Horwitz indicates that we all have beliefs about how we learn a foreign language, and about the strategies we use to achieve its learning. These beliefs can become obstacles to language learning if they have been formed as a result of negative experiences. Altan [10] and Murphy, Delli and Edwards [11] coincide in pointing out that it is during the educational process, particularly at the beginning of this process, when students' beliefs can be intervened, in order to identify those that favor academic results and those that do not. The beliefs of the students have an important impact on their performance, and the latter in turn feed the generation of new beliefs regarding the learning of a foreign language. Horwitz [9] in his study designs a questionnaire that addresses the beliefs of the subjects in the following areas:

1. Aptitude towards the learning of the foreign language: beliefs about the success and/or failure that can be had in front of the learning of the language. Aptitude towards learning a foreign language is a fundamental factor that can contribute significantly to determining language development in a second language student. Indicating that someone has an aptitude to learn a language means that that person has a good chance of being successful in that task. In this sense, the type of belief, positive or negative, about the aptitude for a language can explain, in part, its school successes and failures.

2. Relationship with the language: beliefs about the need to know and get involved in the English-speaking culture to be able to speak the language. Relating to the foreign language requires the student to appreciate the social and cultural meanings that the English language conveys. Since Beninese students do not have a close connection with the English-speaking culture in their socio-educational environment, it is necessary for the language teacher to develop communicative activities in the classroom that allow students to immerse themselves in the English language [12].
3. English communication strategies: beliefs related to the strategies and ways of learning that are necessary to acquire the language. For the learning process of a language, it is essential to teach appropriate cognitive and metacognitive strategies, which facilitate the student's acquisition of the language and the Englishspeaking culture. These strategies are defined as a set of tools, often conditioned to a learning style, that allow an individual to solve a problem. There is a lot of research on student learning success, however, the main conclusion is that the strategies used to learn are different and are best learned when the right strategy is applied.

4. Motivation and expectations: beliefs about the importance that the students assign to the learning of the foreign language and to the degree of utility that this means for their lives. Success in acquiring a language depends, among other factors, on motivation, that is, the desire to learn the language and the adaptation of the English-speaking culture to its own context. In other words, the importance that a subject assigns to learning a foreign language will depend on how close they are to the language, the desire to acquire it and the influence of their sociocultural environment.

5. Anxiety in the classroom: beliefs related to fear reactions and concern for certain situations or people. When developing a second language, some people react anxiously, which generates emotions of worry, tension and fear. One of the causes of poor academic performance is the fear that students may feel. Anxiety and fear are emotional factors that affect the acquisition of a foreign language in a positive or negative way, since the stress present in learning can be due to fear or motivation.

Beliefs are formed early and tend to selfperpetuate, and people develop a belief system that houses all those acquired by the process of cultural transmission. Knowledge and beliefs are intrinsically related. However, the affective, evaluative and episodic nature of beliefs makes them become a filter through which new phenomena are interpreted. Beliefs are prioritized, according to connections or relationships, with other beliefs or other cognitive and affective structures. They are instrumental in the definition of tasks and the selection of cognitive tools with which to interpret, plan and make decisions regarding tasks. In sum, beliefs strongly influence perception.

\section{METHODOLOGY}

This study is framed in the qualitative paradigm and addresses the understanding of the phenomenon of beliefs about learning English by primary school students in Beninese primary schools. It corresponds to an interpretive case study, that is, it is the study of the particularity and complexity of a singular case, in order to understand its activity in specific circumstances. 
The main objective of this study is to identify the beliefs about the teaching and learning of English as a foreign language of four groups of primary education students (CE1 (Cours Elémentaire 1ère année), CE2 (Cours Elémentaire 2ème année), CM1 (Cours Moyen 1ère) and CM2 (Cours Moyen 2eme)) selected from a private primary school from the Littoral region.

Participants were selected as follows: twentythree students from CE1, twenty-one subjects in CE2, twenty-four in CM1 and sixteen in CM2 were students. Their ages ranged from eight to fourteen years. Of the eighty students, forty-one are girls while forty-three are boys.

Students in each class have two hours of English of forty-five minutes each, per week. One of them is regular classroom hour, where students learn the four communicative skills of the English language: reading, writing, listening and speaking. The other hour is designated as a workshop, to carry out practical work related to the linguistic content that is being worked on in the other two regular hours.

To collect data on students' beliefs, the focus group technique was used, with open-ended questions, guided by the categorization of the instrument called Beliefs about Language Learning Inventory, created by Horwitz [9] and whose organization is detailed below, according to the following categories:

1-Aptitude towards learning the foreign language: beliefs about the success and/or failure that they may have in front of learning the language.

2-Relationship with the language: beliefs about the need to know and/or get involved in the Englishspeaking culture to be able to speak the language.

3-English communication strategies: beliefs related to the strategies and ways of learning that are necessary to acquire the language.

4-Motivation and expectations: referring to the importance that students assign to learning the foreign language and the degree of usefulness that it implies in their lives.

5-Anxiety in the classroom: reactions of worry, fear and anxiety that affect the acquisition of the language.

The focus group technique was applied to each course and consisted of a set of questions related to the objective of the study. It lasted forty minutes for each course. Before starting the focus group, the students were informed about what a focus group was, and how it would be carried out. It was also reported that the interview would be recorded.
The data were analyzed following the fundamental sequence of the content analysis that establishes the following steps for data treatment: transcription, segmentation, saturation, coding and categorization. The results of the content analysis were subjected to the triangulation of five researchers in search of the reliability of the data. These researchers are university academics who have carried out content analysis in their studies. Therefore, their experience as researchers contributed to give greater reliability to the analyzes of this study.

\section{DISCUSSIONS OF RESULTS}

In order to organize the data obtained through the focus group discussions carried out, discussions are organized under themes that are presented.

\section{Importance of language learning}

In CE1 and CE2, students express the need to use the language for their professional future, to help foreigners or to use it when traveling abroad. In CM1 and CM2, they consider the language relevant for the support it can provide them in their studies, work, and social and cultural life. More precise and clear ideas of the students are observed in front of the benefits that they could obtain from the handling of English, as they advance in age and schooling, since the group of CM2 is able to recognize the opportunity of access to other socio-cultural groups, which gives them command of the language.

The usefulness of English for students is related to that indicated by Álvarez and Bassi [13], regarding access to better opportunities and better quality intercultural communication. Attitude towards learning a foreign language, on the other hand, is a fundamental factor that helps determine language development in a student. The attitude of the students in front of the language is outlined with their expectations, the levels of anxiety that this generates and their motivation, that is to say, as a whole, these three factors would determine if a subject has aptitude towards the language, and consequently, it would help to predict the academic success of the person in their learning [14]

In CM1, statements of indifference towards learning English were observed among a group of students. Leithwood et al. [15] emphasize that students should be aware of the usefulness of mastering a foreign language and a clear vision and goals of what they want to achieve with it. In other words, in order to promote the learning of a language, it is important to keep in mind the contribution that it will make in the student's life. However, in CM1 and CM2, some students report the following:

Koffi (CM1): I don't think it is that important [English], because what if one [refers to oneself] can work in Benin and stay a lifetime? 
Nassi (CM1): ... I find that for what I want to study [...], I don't need English...

These fragments show the disinterest on the part of some students regarding the learning of the foreign language, since their beliefs are firmly rooted in the fact that the language will not be fundamental in their lives, since they live in a French-speaking country. This is related to what McBride [16] points out in that students should be aware of the use of the foreign language and its socio-communicative utility. As can be seen in the responses of the focus groups, some students believe that the language may not be relevant in the professional field. A fact that could also influence the statements of the participants is the status of the English language in the educational project, since one of the challenges facing the teaching of English is a certain perception on the part of the student body: it is considered less important than other subjects traditionally called the main ones, such as mathematics and language.

As students age, the positive assessments against the utility of English increase slightly. This could mean that the way in which people give meaning to the subject implies starting with the identification, supplementation and placement of the new information in its previous cognitive structure $[17,4]$.

\section{Closeness to English as a foreign language}

Most of the primary school student participants report having closeness to the language through technology: video games, music, movies, and television series. Faced with this, it is evident that the approach to the language is achieved through these technological resources, with the consequent liking or disliking that this type of communication causes in them. However, in CM1 and CM2, students tend to indicate:

Dossi (CM2): I don't listen to as much music in English....

Katé (CM2): I don't like English....

Tomi (CM2): I am not attracted to the language...

Massé (CM2): I don't like English, I don't hear anything, I don't see anything in English...

Since Benin is a French-speaking society, the possibilities for student interaction with Englishspeaking speakers are limited. This could have an important impact on the reasons given by students for their dislike for the language, since they do not see the specific need to learn a foreign language that they do not use in their daily life. From the point of view of sociocultural theory, the relevance of the context and the environment in which students find themselves in order to learn a foreign language in a significant way is highlighted. The social environment can be a positive or negative factor in learning English [18, 19].
Various studies on language learning highlight [20] how influential it can be in learning as well as in the family and educational contexts in which the foreign language student is situated, the frequency with which they approach to the language and the constant usefulness it can give it. Broadfoot et al. [21] point out that if both family and school are learning contexts for the language, they become a stimulus for the student to be active, constructive and collaborative. They develop a spirit of overcoming mistakes and maintaining a constant motivation for learning. This is often visualized in what is expressed by the participants in this study, regarding their dislike for English and their lack of closeness to the language in everyday life.

\section{Learning experiences}

The students' previous learning experiences are varied in each course and very different from one level to another. In CE1, students express having had positive and entertaining learning experiences.

Irma (CE1): good, quality experiences... .

In CE2, the subjects stated that they had had classes that were too elementary for their level, in previous years. Syli (CE2): ...when I was younger, they would pass to us little pictures in the English course ...

Likewise, those in CM1 add having had English classes late:

Yvette $(\mathrm{CM} 1): .$. when $\mathrm{I}$ was in the other school from Nursery1 to CE2, it seems that it was a workshop, so it was like basic and I didn't learn much.

In $\mathrm{CM} 2$, they express comments similar to the previous ones, adding having had negative learning experiences:

Paul (CM2): The classes were horrible; he didn't even explain us very well....

These negative experiences when learning English represent a cause-effect relationship, that is, unfortunate learning situations in the training of students, causing them to develop negative beliefs about what it means to learn a foreign language. Students create internal representations of their experiences and these determine their actions and thoughts when learning the language. Conversely, those who learn a language deeply through positive learning experiences generate positive perceptions and achieve better academic results [22, 23].

In participants' responses, a very low frequency of statements regarding positive experiences can be visualized, that is, learning situations from which the subjects perceive that they have learned something new about the language. CE1 and CE2 students report, for example, having lived these kinds of English learning experiences during their schooling. 
Adissa (CE1): ...over time we have been learning more things ....

Mili (CE2):... English classes have been entertaining... (6th year).

Kotchivi (CM2): ... sometimes English classes were entertaining ...

CM2 students do not report positive experiences in language learning. However, the negative perceptions of students with the learning of English are increasing per course very noticeably, that is, the number of negative experiences of students in CM2 is greater than the number of negative experiences of students in CE1. Some of them have presented their views:

Kuaku (CE1): ... in the English class it was all fast and the next day we passed another subject ....

Dada (CE2):... in the English classes they passed us pure drawings....

Firmin (CM1):... before they taught everything in French in the English class....

Sèssi (CM2): ...they passed the subject in the English class, but they never explained it....

The negative situations that the participants declare in the previous fragments constitute previous learning experiences that translate into mental images that are retained and can be evoked and become relevant in the student's performances [24]. This corresponds to the type of beliefs that learners have about learning the language, a product of the previous experiences they have obtained with the development of the foreign language, since in CE1 and CE2, the students have experienced better experiences than in CM1 and CM2. The earlier the acquisition of a belief, the more difficult it will be to try to modify it, since it has a great influence on the information process [25].

\section{Communication in English}

In the focus group, a hypothetical situation arises: if at this moment you won a scholarship to an English-speaking country, how would you communicate with people? CE1 and CE2 students point out that they would put what they have learned into practice in order to start some kind of conversation in English. By contrast, CM1 and CM2 students say they would use a google translator or dictionary. It is possible to visualize in the responses of the subjects the involution of their discourses regarding direct conversation in English.

Chabi (CE1):... with what we have learned in school, I would try to communicate....

Bona (CE2):... I would apply what I know and the translator....

Momo (CM1):... would take a translator....

Toni (CM2):... would use a dictionary...

Ablavi (CM2): ... would use the cell phone application....
Participants' previous answers explain that as they advance in school they take on the challenge of starting a conversation in English only with the help of some external resource (dictionary or translator, for example). Only in CE1 do they dare to take on this task of applying what they have learned in school autonomously [26, 27]. In sum, the belief of the students is centered on the fact that communication in English is synonymous with translating the foreign language with some kind of support. This argument can be supported with the statements of students from CM1 and $\mathrm{CM} 2$ who express insecurity to engage in fluent conversation in English and the repercussions that this generates during classes: feelings of anxiety, shame, nervousness and teasing.

Fifa (CM1):... I am reluctant to speak in English, because when I say the wrong word everyone laughs. Cossi (CM2): ... teasing and laughter also affect ....

\section{Motivation for language learning}

Students' motivation to learn English more and more is concentrated in CE1 and CE2. However, some students show a significant lack of motivation regarding the language.

Foumi (CE1): in English I feel tired, because it is always in the last hour of the day.

Sado (CE2): ... I get bored ....

Kouagou (CM1):... it is not compulsory to learn English, because if one does not like English and does not want to, one does not study....

Worou (CM2): ... I do not understand English ...

Gnon (CM2):... in every way [the English classes] were bad, in teaching....

The above statements are related to the lack of motivation and lack of interest that English classes generate in students, a situation that seems to reveal problems with the teaching strategies used by teachers in the classroom. In this sense, the learning environment in a foreign language class is essential for a student to learn and feel comfortable experimenting with the language. Furthermore, the responses of the students are related to what Messakimove [8] and Pizarro [28] propose regarding the beliefs that are generated as a result of previous experiences of learning a foreign language.

Students have had negative experiences when learning English and the only closeness to the language is through music, movies and games, that is, they do not have a familiarity with the foreign language where they can directly practice the language. Various authors have referred to how relevant are the variables that influence motivation for learning a second language, elements such as social integration, communication needs, attitudes, curiosity, interest, are some of the factors involved in the process of acquiring English [7]. 
González et al. [22] reveal one of the reasons why students leave their studies abandoned: their low motivation and disinterest. On the contrary, motivation generates future achievements. Examples of motivation are observed by CE1 and CE2 students who express feeling motivated to learn the language.

M'po (CE1):... I am eager to learn....

Ablam (CE1):... I am happy to learn another language...

Bignon (CE2):... each class is learning more....

However, the lack of motivation in CM1 and CM2 is remarkable in comparison to the other groups of students. Most CM1 and CM2 students express disinterest in English.

Semassa (CM1):... I am not attracted to the language. Gado (CM1): ... I'm embarrassed when talking about it ....

Moussiliou (CM2): ... I am bored by English ....

Djessou (CM2): ... I don't listen to as much music in English, because I don't like it ....

The hypotheses of Guay et al. [29], according to the theory of self-determination, states that if students have a high degree of motivation, this will have positive results at an academic level, and will be reflected in behavior, optimism and stimulating experiences. The lack of motivation of CM1 and CM2 students, evidenced in the fragments just mentioned, are a reflection of their beliefs about language learning and nonchalant behavior towards English, which obviously have repercussions on language acquisition. On the other hand, the positive attitude and motivation that CE1 and CE2 students maintain has its effect on their attitude towards English, their interest in speaking skills and their academic results.

\section{Nervous reactions against error}

As for the anxiety that students have during English classes and/or some oral activity, everyone agrees to feel nervous about making a mistake or pronouncing the wrong way. In CM1 and CM2, they state that the nerves they feel are purely for fear of the ridicule and laughter they may receive from their peers.

Dado (CM1): ... I am afraid they will make fun ....

Sita (CM2): ... I don't like it, because one is wrong and in the course everyone makes fun ....

Anxiety is a feeling of tension regarding the development of language skills in the foreign language. This has a negative impact on learning English, since it causes $\mathrm{CM} 1$ and $\mathrm{CM} 2$ students to be insecure and fearful of speaking skills. Roncel [30] recognizes the psychophysiological exponents of anxiety, indicated by the students in the group interview: fear, sweating, palpitations and memory loss. According to the author, this is related to anxiety in language classes and its impact on the deterioration of communication strategies, low oral comprehension and expression, forgetfulness and mistakes.

Participants' responses to anxiety are varied, but significant, since from CE1 to CM2 they often point to fear of speaking skills in English. In this sense, various authors refer to anxiety and fear as emotional factors that affect the acquisition of a foreign language in a positive or negative way, since the stress present in learning can be due to fear or motivation [31-33]. One of the causes of poor academic performance is the fear or anxiety that students may feel $[13,34,35]$. This is related to what is expressed by the CM1 and CM2 students, who mention feeling fear in the face of ridicule and mistakes, which results in a lack of motivation in the development of oral expression.

\section{CONCLUSION}

The results and subsequent analysis of the statements obtained by participants during the focus group reveal the challenges that learning a foreign language presents for primary school students. The English language is viewed by CE1 and CE2 students as an important tool for future professional life, in terms of the opportunities it can provide; however, CM1 and CM2 students question the real importance of language in their future professional lives.

That is, CE1 and CE2 students seem to be a first stage clearly characterized by the interest and motivation of the students with respect to the foreign language and CM1 and CM2 students would constitute a second stage in which the students explain their disinterest and lack of motivation for learning the language. This could have an explanation associated with the psychobiological processes that the students go through, who as a result of their growth, become critical and sensitive individuals of their environment and of the people that constitute it. This point is also linked to the status of the language in our society, the learning of the English language is highly desirable from the discursive aspirations of our society, however, the social context, almost entirely French-speaking, does not offer real opportunities for communicative interaction in a language other than French, at the level of primary schools.

A second aspect revealed by the data is that students establish a contact with the language, outside the classroom, through technological resources, which provide practice in the use of receptive skills, not in productive language skills. Again, it is appreciated that regarding the closeness of the students to the language, those of CE1 and CE2 feel closer than those of CM1 and $\mathrm{CM} 2$.

There is a third aspect that obviously occurs due to the increase in student education. CM1 and CM2 students report a greater number of negative 
Jean-Marc Gnonlonfoun; J Adv Educ Philos, April., 2020; 4(4): 147-154

experiences with learning English than CE1 and CE2 students. The students in CM1 and CM2 believe that their English classes in previous years have been elementary and that their language learning has been low. The criticisms of these students regarding their teachers' teaching strategies and the use of French by them for conducting English classes are evident. It is worth mentioning that one of the great weaknesses of teaching and learning English in primary schools is the lack of primary teachers with adequate command of the language and teaching and assessment strategies that are in harmony with the communication and learning needs of students. . Most of the teachers who teach English at this educational level are secondary school teachers, with the corresponding consequences that this situation may have on teaching and the perception that students have of the language.

It is also interesting to note as a fourth fundamental aspect, the belief of the CM1 and CM2 students that when they need to communicate in English they will use the available technological resources. This is clearly consistent with the general idea of many individuals that technology could solve communication problems, that is, it would not only be a support tool, but one that solves any lack of communication. Clearly, a last point that is central to the success of learning a foreign language is the nervousness and anxiety caused by students speaking another language in front of their peers, and particularly the ridicule they may receive from them. This is an unaddressed point in the process of teaching and learning English in our primary education. This last point becomes relevant, since the previous experiences that the students have lived during the learning of the language are generating expectations and beliefs about the learning of English, which many times can become truths that hinder future learning. It is therefore important to recommend that the ability of English teachers to create learning environments free of ridicule and situations that generate negative anxieties in students be reinforced.

\section{REFFERENCE}

1. Brown, A. (2009). Students 'and teachers' perceptions of effective foreign language teaching: A comparison of ideals. The Modern Language Journal, 93(1), 46-60.

2. Chan, K. W., \& Elliott, R. G. (2004). Relational analysis of personal epistemology and conceptions about teaching and learning. Teaching and Teacher Education, 20(8), 817-831.

3. Cho, Y. H., Lee, J., \& Jonassen, D. H. (2011). The role of tasks and epistemological beliefs in online peer questioning. Computers \& Education, 56(1), 112-126.

4. García, G. (2011). Anxiety in learning a second language. Autodidacta Magazine, 1(5), 41-55.

5. Carrero, C. P. A., \& Pongutá, D. C. (2010). Exploring students' beliefs about learning English in two public institutions. Cuadernos de Lingüística Hispánica, (15), 77-92.

6. Harmer, J. (2011). The practice of English language teaching. England: Longman.

7. Martínez, I. (2005). New perspectives on ELE learning for Japanese: Formal awareness. (Thesis to choose the degree of Doctorate in Education, Complutense University of Madrid). Recovered from http://biblioteca.ucm.es/thesis/fll/ucmt25559.pdf

8. Messakimove, S. (2009). The beliefs of the Gabonese high school students about their Spanish learning process. Marco ELE Magazine, (9), 1-17.

9. Horwitz, E. (1999). Cultural and situational influences on foreign language learners' beliefs about language learning: a review of BALLI studies. System, 27, 557-576.

10. Altan, M.X. (2006). Beliefs about Language Learning of Foreign Language- Major University Students. Australian Journal of Teacher Education, 31(2), 45-52.

11. Murphy, P. K., Delli, L. A. M., \& Edwards, M. N. (2004). The good teacher and good teaching: Comparing beliefs of second-grade students, preservice teachers, and inservice teachers. The Journal of experimental education, 72(2), 69-92.

12. Larsen-Freeman, D. (2003). Teaching language: From grammar to grammaring. Heinle \& Heinle Pub.

13. Álvarez, H., \& Bassi, M. (2010). Skills for the 21st century. Teaching English in Costa Rica [Article on web page]. Recovered from http://www.iadb.org/es/temas/educacion/habilidade s-para-el-siglo-xxi-la-ensenanza-del-ingles-encosta-rica, 6641.html

14. Lasagabaster, D. (2003). Trilingualism in teaching. Attitudes towards the minority, majority and foreign language. Lleida: Millennium.

15. Leithwood, K., Day, C., Sammons, P., Harris, A., \& Hopkins, D. (2006). Successful school leadership: What it is and how it influences pupil learning.

16. McBride, K. (2009). Student perceptions of the techniques used in teaching English as a foreign language. Universum Magazine, 2(24), 94-112.

17. Rubio, F. (2004). Anxiety in language learning. Huelva: University of Huelva.

18. Gao, X. (2006). Understanding changes in Chinese students' uses of learning strategies in China and Britain: A socio-cultural reinterpretation. System, 34(1), 55-67.

19. Lantolf, J. P., \& Thorne, S. L. (2006). Sociocultural theory and the sociogenesis of second language development.

20. Weinstein, C. E., Husman, J., \& Dierking, D. R. (2000). Self-regulation interventions with a focus on learning strategies. In Handbook of selfregulation (pp. 727-747). Academic Press.

21. Broadfoot, P. M., Daugherty, R., Gardner, J., Harlen, W., James, M., \& Stobart, G. (2002). 
Assessment for learning: 10 principles. Cambridge, UK: University of Cambridge School of Education.

22. González, C., Montenegro, H., \& López, L. (2012). Analysis of the reliability and validity of the course experience questionnaire (CEQ). Educación $y$ Educadores, 15(1), 63-78.

23. Prosser, M., \& Trigwell, K. (2006). Confirmatory factor analysis of the approaches to teaching inventory. British journal of educational psychology, 76(2), 405-419.

24. Sanchez, H. S. (2010). An investigation into the relationships among experience, teacher cognition, context, and classroom practice in EFL grammar teaching in Argentina(Doctoral dissertation, University of Warwick).

25. Gonzalez Afonso, M. C., Alvarez Perez, P. R., Cabrera Perez, L., \& Bethencourt Benitez, J. T. (2007). Dropout in university studies: determinant factors and preventives measures. Revista espanola de pedagogia, 65(236), 71-85.

26. Martínez-Fernández, J. R., \& García-Ravidá, L. (2012). Learning patterns in university students of the master's degree in secondary education: related personal and contextual variables. Profesorado magazine, 16 (1), 166-182.

27. Pérez, Y., \& Barba, M. (2010). The moodle platform and its use in the development of communicative competence in the English language. E-Curriculum Magazine, 6(1), 1-25. Recovered from http://www.redalyc.org/pdf/766/76619157008.pdf

28. Pizarro, M. (2010). An approach to the study of the beliefs of foreign language teachers. Decires
Magazine. Magazine of the Teaching Center for Foreigners, 12(15), 27-38. Recovered from http://revistadecires.cepe.unam.mx/articulos/art153.pdf

29. Guay, F., Ratelle, C. F., \& Chanal, J. (2008). Optimal learning in optimal contexts: The role of self-determination in education. Canadian Psychology/Psychologie canadienne, 49(3), 233.

30. Roncel, V. (2008). Self-concept, anxiety and motivation in the language classroom. Marco ELE Magazine, (7), 1-20.

31. Sheen, Y. (2008). Recasts, language anxiety, modified output, and L2 learning. @Language Learning, 58 (4), 835-874.

32. Tallon, M. (2009). Foreign language anxiety and heritage students of Spanish: A quantitative study. Foreign Language Annals, 42(1), 112-137.

33. Arnaiz, P., \& Guillén, F. (2013). Anxiety in Spanish EFL students in different university degree programs. Anales de Psicología/Annals of Psychology, 29(2), 335-344.

34. Garcia, M., \& Sebastián, C. (2011). Epistemological beliefs of pedagogy students in preschool, basic and secondary education: Differences in initial teacher training? PSYKHE Magazine, 20(1), 29-43.

35. Mizala, A., \& Torche, F. (2012). Bringing the schools back in: the stratification of educational achievement in the Chilean voucher system. International Journal of Educational Development, 32(1), 132-144. 